\title{
Six low-penetrance SNPs for the estimation of breast cancer heritability: A family-based study in Caucasian Italian patients
}

\author{
SIMONA DE SUMMA ${ }^{1 *}$, FRANCESCA GRAZIANO ${ }^{2 *}$, BRUNELLA PILATO $^{1}$, \\ ROSAMARIA PINTO $^{1}$, KATIA DANZA ${ }^{1}$, ROSANNA LACALAMITA ${ }^{1}$, SIMONA SERRATİ ${ }^{1}$, \\ DOMENICO SAMBIASI $^{3}$, MARIO GRASSI $^{2^{*}}$ and STEFANIA TOMMASI ${ }^{1 *}$ \\ ${ }^{1}$ Molecular Genetics Laboratory, IRCCS, Istituto Tumori ‘Giovanni Paolo II', I-70124 Bari; \\ ${ }^{2}$ Department of Brain and Behavioral Sciences, Section of Biostatistics, NeuroPhysiology and Psychiatry, \\ Unit of Medical Statistics and Genomics, University of Pavia, I-27100 Pavia; \\ ${ }^{3}$ Familial Hereditary Cancer Study Unit, IRCCS, Istituto Tumori ‘Giovanni Paolo II', I-70124 Bari, Italy
}

Received December 28, 2016; Accepted March 3, 2017

DOI: $10.3892 / 01.2017 .6725$

\begin{abstract}
Breast cancer is a malignancy with a strong heritable component. Genetic counseling has been principally focused on families carrying high-penetrance breast cancer $1 / 2$, early onset genes. Current modeling suggests that the majority of the unexplained fraction of familial risk is likely to be explained by a polygenic model. The aim of the present study was to estimate the heritability $\left(\mathrm{h}^{2}\right)$ of breast cancer susceptibility through the analysis of 6 single nucleotide polymorphisms (SNPs), nuclear mitotic apparatus protein 1 , cyclin D1, cytochrome C oxidase copper chaperone, fibroblast growth factor receptor 2, TOX high mobility group box family member 3 and solute carrier family 4 member 7 . These 6 SNPs, previously identified by genome-wide association studies, were considered to evaluate the additive and common environmental components that contribute to the development of breast cancer in nuclear (pedigrees including only first degree relationships) and in extended families (with at most third degree relationships). A total of 22 extended pedigrees, subsequently split into 52 nuclear pedigrees were analyzed. An example of splitting process from extended to nuclear pedigree is shown in Fig. 1. Firstly, an underline latent continuous trait $\left(Y^{*}\right)$ using breast cancer status and information of 6 breast cancer-associated SNPs was calculated. This
\end{abstract}

Correspondence to: Dr Stefania Tommasi, Molecular Genetics Laboratory, IRCCS, Istituto Tumori 'Giovanni Paolo II', Viale Orazio Flacco 65, I-70124 Bari, Italy

E-mail: s.tommasi@oncologico.bari.it

${ }^{*}$ Contributed equally

Abbreviations: $\mathrm{BC}$, breast cancer; IDC, invasive ductal carcinoma; DCIS, ductal carcinoma in situ

Key words: heritability, breast cancer risk, familial breast cancer, single nucleotide polymorphisms, familial study novel trait summarized the susceptibility of breast cancer in each individual. Secondly, the $\mathrm{h}^{2}$ of $Y^{*}$ was estimated using an additive polygenic-common environment-unique error model. $\mathrm{h}^{2}$ was evaluated in extended and immediate pedigrees, obtaining comparable results. $\mathrm{h}^{2}$ accounts for $\sim 40 \%$ of the total phenotypic variance, indicating a fairly strong additive genetic effect of breast cancer susceptibility. The present study indicated the importance of the evaluation and consideration of these six SNPs, which can be used as instrumental variables in order to obtain improved genetic models that are useful for $\mathrm{h}^{2}$ analysis.

\section{Introduction}

Breast cancer (BC) is one of the most commonly diagnosed types of malignancy following non-melanoma skin cancer worldwide, as reported in GLOBOCAN 2012 (1). BC is a disease with a strong heritable component. Risk increases with the number of affected relatives, age at diagnosis and the number of affected male relatives (2-5). Genetic counseling has principally focused on families with a history of breast cancer that have a risk of carrying alterations in high-penetrance breast cancer 1 , early onset (BRCA1) and breast cancer 2 , early onset (BRCA2) genes, that are associated with the highest lifetime risk. However, only $25 \%$ of the familial aggregation of $\mathrm{BC}$ is explained by known high- and moderate-risk genes (6). For this reason, genetic testing leads to uninformative results in a number of patients. Numerous efforts have been made by consortia, including the Consortium of Investigators of Modifiers of BRCA1 and BRCA2 (7) and the Breast Cancer Association Consortium (8), to explain the remaining heritable risk through genome-wide association studies (GWAS).

However, GWAS results only collectively explain a small part of the estimated hereditability. It is of note that GWAS were conducted in the general population and that patients affected by familial BC constitute a different group of risk. Sawyer et al (9) analyzed 22 single nucleotide polymorphisms (SNPs), which were previously identified through GWAS to be involved in increasing the risk of developing $\mathrm{BC}$ in a cohort of 1,143 index patients with BRCA1/2 alterations and 
BRCAX indices (patients with family history of BC but with no mutation in BRCA1/2 genes). It was demonstrated that the magnitude of the effect of the SNPs was greater compared with those described through population-based studies and, in addition, the authors identified for the first time an application of GWAS results (9). However, the study conducted by Sawyer et al (9) only considered index patients, and not their relatives and the shared environmental factors.

Family-based studies provide several opportunities for the investigation and interpretation of the numerous, but at present unidentified, genetic variations underlying complex diseases. This type of study allows heritability $\left(\mathrm{h}^{2}\right)$ to be estimated, which is formally defined as a ratio of variances, or more specifically as the proportion of total variance in a population for a particular measurement, obtained at a particular time or age that is attributable to variation in additive genetic values (10).

In order to investigate $\mathrm{BC} \mathrm{h}^{2}$, a family-based study analyzing 6 SNPs whose association with BC risk was previously identified by GWAS and confirmed by Sawyer et al (9) was performed. The reason for studying the $\mathrm{h}^{2}$ of $\mathrm{BC}$ is that at present, 20 risk alleles have been identified (11-14) to be associated with $\mathrm{BC}$ risk, however these results have not yet been integrated into clinical practice. Common low-penetrance BC susceptibility alleles have been implemented in different BC Risk Assessment Tools (15-19), however no improvement in model performance has been exhibited $(20,21)$. Thus, the primary aim of the present study of BC in Caucasian families was to verify the opportunity to implement a procedure for $\mathrm{h}^{2}$ estimation based on GWAS-identified BC alleles.

\section{Materials and methods}

Study population. A sample of 22 patients at high risk of carrying BRCA mutations were enrolled from the Counseling Program of IRCCS Istituto Tumori 'Giovanni Paolo II' of Bari between March 2008 and September 2011, following the specific criteria summarized in Table I. Genealogical information and medical history were registered to each participant. Genetic information and the tumor-node-metastasis staging (22) of breast cancer are also available for the analysis (Table II). All patients enrolled were characterized according to pathological features and family history, and were classified as having an increased risk to carry BRCA mutations (10-20\%) by BRCAPRO software (19). On the basis of genealogical information, 22 extended and 56 nuclear pedigrees were developed for each patient (Table II). An extended pedigree is represented by each index enrolled in genetic counseling and all relatives of all degrees. Every extended pedigree was split into several nuclear pedigrees, each including only first-degree relatives.

Ethics approval and patient consent. Written informed consent was obtained from all participants. The present study was approved by the Ethics Committee of the IRCCS-Istituto Tumori 'Giovanni Paolo II' (Prot. N56/CE; 06/05/2011) to perform molecular analyses and use data for research purposes.

BRCA genes sequencing and SNP genotyping. Genomic DNA was extracted using QIAmp DNA blood midi kit (Qiagen, Inc.,
Valencia, CA, USA) according to the manufacturer's protocol. DNA was quantified using a ND-8000 Spectrophotometer (NanoDrop Technologies; Thermo Fisher Scientific, Inc., Wilmingtom, DE, USA) and mutational screening was performed (23). If a variant was identified in the index patient, the consent to inform other family members was requested. The blood of all enrolled members, healthy or affected, were analyzed for the identified variant in the index patient. The variants identified in the sequence were characterized and compared with those present in the online databases Breast Cancer Information Core (http://www.research.nhgri.nih. gov/bic/), ENTREZ SNP (http://www.ncbi.nlm.nih.gov), Ensemble Database (http://www.ensembl.org) and the Human Genome Variation database (http://hgvbase.cgb.ki.se/).

SNP genotyping (rs3018301, rs614367, rs6504950, rs2981582, rs3803662 and rs4973768) was performed through TaqMan assays (Thermo Fisher Scientific, Inc., Waltham, MA, USA), according to the manufacturer's protocol. SNPs information are summarized in Table III.

Statistical analysis. A generalized linear model was applied to each of the 6 SNPs. Data are presented as the mean \pm standard error of the mean for continuous variable and for categorical data. The association between genotyped SNPs and BC was tested using a generalized mixed linear model using R software (version 3.1.3) (24). As the traditional variance components model for dichotomous phenotypes demands a high number of cases, a two-step approach was adopted.

First step: From binary to continuous score trait. A BC susceptibility score was obtained using a liability threshold model. This model assumed that under dichotomous disease information there was a hypothetical continuous liability composed of latent genetic and environmental factors (25). In particular, for each subject the susceptibility score $Y^{*}$ was calculated, which summarizes disease status (affected or unaffected) and information on six disease-associated SNPs. In order to estimate $\mathrm{h}^{2}$, it is mandatory to have a continuous and normal distribution. Generally, such variables depend on the presence of a number of binary response variables from which a latent variable may be calculated (25). In the present study, a binary variable (disease status) and information regarding disease-associated SNPs were available. Thus, these were used as instrumental variables to obtain a novel variable, $Y^{*}$, and a Gaussian continuous variable $\mathrm{N}(0,1)$ underlying to disease status. Specifically, the disease status $Y$ coded $(0=$ affected, $1=$ not affected) is linked to $Y^{*}$ by a threshold $\tau$ :

$$
Y=\left\{\begin{array}{lll}
0 & \text { se } & Y^{*}<\tau \\
1 & \text { se } & Y^{*} \geq \tau
\end{array}\right.
$$

$Y^{*}$ is linked to the six SNPs additively coded $(X=0,1,2)$ by

$$
Y^{*}=\sum_{j=1}^{p} \beta_{j} X_{j}+U
$$

In other terms, $Y^{*}$ includes the liability of $\mathrm{BC}$ predicted by the SNPs of BC and unobserved terms $U$ representing the liability of BC variation unexplained by SNPs. Computations were carried out by Mplus software (version 6.0; Muthen and Muthen, Los Angeles, CA, USA) (26), and the Mplus output 

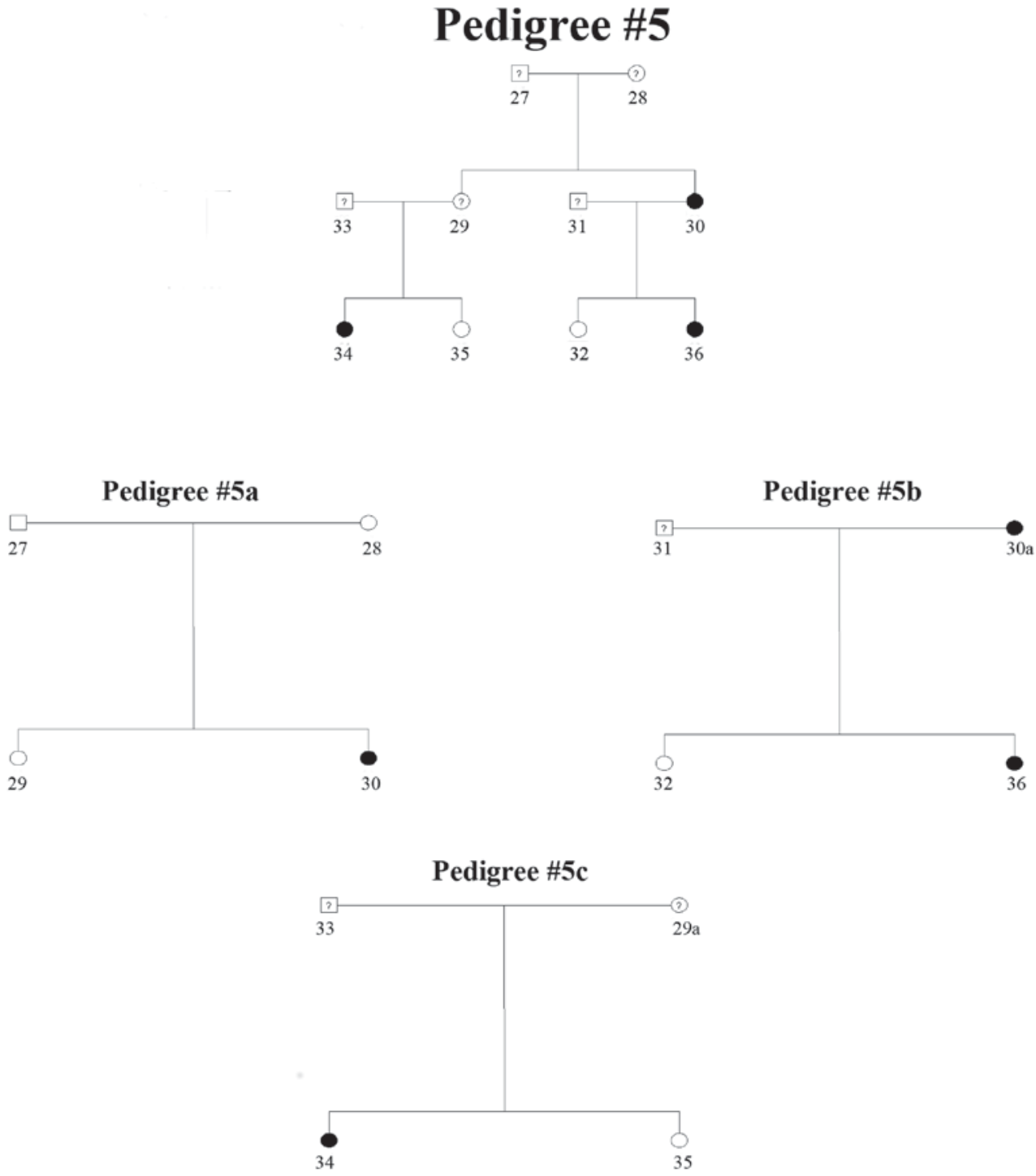

Figure 1. Example of one extended pedigree (family \#5) with 10 subjects (first section) and two nuclear pedigrees following the splitting process (second section). Identities flanked by letter are the same individuals of the extended pedigree. They were renamed to perform analyses on nuclear pedigrees.

scores for each subject for the latent response $Y^{*}$ is the outcome variable for hereditability analysis used in the second step.

Second step: $h^{2}$ and $c^{2}$ estimations. In the second step, individuals were not considered independently, but associated with each other by drawing pedigrees. A total of 22 extended families (52 nuclear families) were used to estimate the genetic component of the susceptibility of BC. $\mathrm{h}^{2}$ analysis was carried out by the variance component analysis algorithm implemented in the genetic analysis software SOLAR (version 6.0; Southwest Foundation for Biomedical Research, San Antonio, TX, USA) (27), assuming an Additive polygenic-common environment-unique error (ACE) model and adjusting for sex and age (28). SOLAR was performed with extended pedigrees and nuclear pedigrees. Therefore, a variance component $\left(\mathrm{c}^{2}\right)$ was adopted to denote the variance among family members due to a common cluster environment, using extended pedigrees, and the variance between siblings due to a common sibling environment, using nuclear pedigrees.

\section{Results}

The demographic characteristics and BRCA1/2 mutational status of the enrolled 144 subjects ( 52 patients with breast cancer) are described in Table IV. Regarding the observed odds ratio of the BRCA1/2 and the six SNPs no significance was observed.

$h^{2} . h^{2}$ effects were estimated in extended and nuclear families (22 and 52 pedigrees, respectively) through SOLAR using the liability scores $Y^{*}$, that were normally distributed, as expected. The scores were interpreted only as the liability variation of BC unexplained by SNPs, as no significant SNPs results were observed (Table IV). The results from the analysis of the extended and nuclear pedigrees are summarized in Table V.

Extended pedigrees. $\mathrm{h}^{2}$ estimation in extended pedigrees is demonstrated in Table V. $\mathrm{h}^{2}$ without covariates was significant and equal to $40.7 \%$. $\mathrm{h}^{2}$ was increased compared with the model without covariates and also significant when sex and age are 
Table I. Familial and clinical criteria used to enroll patients in the Genetic Counseling Program.

Index features Hereditary-based criteria

Patients $<50$ years old with BC

Patients $>50$ years old with BC

Patients with ovarian/fallopian tube carcinoma
1 first-degree relative $<50$ years old with $\mathrm{BC}$

2 first-degree relatives with $\mathrm{BC}$ at any age

1 first-degree relative with OC or fallopian

tube carcinoma at any age

To be enrolled for the program, patients had to match one of the 'Index features' and a 'hereditary-based criteria'. BC, breast cancer; OC, ovarian cancer.

Table II. Features of the index patients whose families were involved in the study.

\begin{tabular}{|c|c|c|c|c|c|c|c|c|}
\hline ID & $\mathrm{c} / \mathrm{nc}$ & BRCA1 mutation & BRCA2 mutation & Age GC, years & Histology & Tumor node metastasis & $\mathrm{n}$ & $\mathrm{N}$ \\
\hline \#1 & $\mathrm{c}$ & c.5266dupC & & 60 & IDC & pT2N0Mx & 14 & 3 \\
\hline \#2 & $\mathrm{c}$ & & c.6462_6463delTC & 41 & IDC & pT3N1M0 & 5 & 1 \\
\hline \#3 & $\mathrm{nc}$ & & & 37 & IDC & pT2N0Mx & 3 & 1 \\
\hline$\# 4$ & $\mathrm{c}$ & & c.6447_6448dup & 59 & IDC & pT2N1M0 & 6 & 1 \\
\hline \#5 & $\mathrm{nc}$ & & & 50 & IDC & pT1N1M0 & 10 & 3 \\
\hline \#6 & $\mathrm{c}$ & & c.1772_1775delTTTA & 72 & IDC & pT4N0M0 & 13 & 3 \\
\hline \#7 & nc & & & 65 & IDC & pT1bN0M0 & 5 & 1 \\
\hline \#8 & $\mathrm{nc}$ & & & 48 & IDC & pT2N0Mx & 5 & 1 \\
\hline$\# 9$ & $\mathrm{c}$ & & c.2049_2050delTC & 36 & IDC & pT2N1M0 & 7 & 2 \\
\hline$\# 10$ & nc & & & 36 & IDC & pT1cN0M0 & 11 & 2 \\
\hline \#11 & $\mathrm{c}$ & c.5266dupC & c.5796_5797delTA & 51 & IDC & pT2NxM0 & 8 & 2 \\
\hline$\# 12$ & $\mathrm{c}$ & c.5266dupC & & 43 & IDC & pT1cN1biiiM0 & 5 & 1 \\
\hline \#13 & $\mathrm{c}$ & & c.5796_5797delTA & 42 & DCIS & pT1cN0M0 & 20 & 4 \\
\hline$\# 14$ & nc & & & 62 & IDC & pT1N1M0 & 28 & 5 \\
\hline \#15 & $\mathrm{c}$ & & c.5796_5797delTA & 51 & IDC & pT1N1M1 & 5 & 1 \\
\hline \#16 & $\mathrm{c}$ & c. $181 \mathrm{~T}>\mathrm{G}$ & & 41 & IDC & pT1bN0M0 & 10 & 2 \\
\hline \#17 & $\mathrm{nc}$ & & & 59 & IDC & pT1cN0M0 & 10 & 2 \\
\hline \#18 & nc & & & 55 & IDC & pT2N1M0 & 11 & 3 \\
\hline \#19 & $\mathrm{c}$ & c.5266dupC & & 54 & IDC & pT1cN1M0 & 4 & 1 \\
\hline \#20 & $\mathrm{c}$ & c.5266dupC & & 48 & IDC & pT2N1aM0 & 30 & 7 \\
\hline \#21 & nc & & & 38 & IDC & pT1cN0M0 & 13 & 3 \\
\hline \#22 & $\mathrm{c}$ & c.5266dupC & & 53 & IDC & pT2NOMO & 10 & 3 \\
\hline
\end{tabular}

c, carrier; nc, non-carrier of BRCA1/2 deleterious mutations; Age GC, age of patient at the genetic counseling; n, number of subjects in the index pedigree; $\mathrm{N}$, number of nuclear families in the index pedigree IDC, invasive ductal carcinoma; DCIS, ductal carcinoma in situ .

considered $\left(\mathrm{h}^{2}=46.4 \%\right)$. Finally when BRCA1 and BRCA2 mutational information are considered in the model as covariates, $\mathrm{h}^{2}$ is $46.7 \%$. In the final model, only BRCA1 exhibited a significant contribution. When the household effect was also considered, $\mathrm{c}^{2}$ was not observed to be significant (data not shown).

Nuclear pedigrees. $\mathrm{h}^{2}$ remained significant in the three models using nuclear pedigrees (model with no covariate, adjusted for sex/age and BRCA1/BRCA2) but reduced compared with the extended pedigrees. In particular, $\mathrm{h}^{2}$ without any adjustment was 35.9, 39.4 and $34 \%$ with sex and age covariates and with BRCA1/BRCA2, respectively (Table V). In the final model, only BRCA1 demonstrated a significant contribution. The effect of siblings, or sibling-household effects, $\mathrm{c}^{2}$, such as in extended pedigrees, were not observed to be significant (data not shown).

\section{Discussion}

A number of studies have been focused on the genetics of BC. This malignancy is $\sim$ twice as common in the first-degree relatives of women with the disease as in the general population, consistent with the variation in genetic susceptibility to the disease (29). Inherited mutations in BRCA1/2 genes lead to a 
Table III. Genotyped SNPs for the present study with genome-wide association study OR (95\% CI).

\begin{tabular}{|c|c|c|c|c|c|c|c|c|}
\hline Author, year & Gene & SNP & RefSeq & HGV name & OR & \multicolumn{2}{|c|}{$95 \% \mathrm{CI}$} & (Refs.) \\
\hline Ahmed et al, 2009 & COX11 & rs6504950 & NM_178509.5 & c. $-156-6504 \mathrm{G}>\mathrm{A}$ & 0.76 & 0.61 & 0.96 & (11) \\
\hline Easton et al, 2007 & $F G F R 2$ & rs 2981582 & NM_000141.4 & c. $109+906 \mathrm{~T}>\mathrm{C}$ & 1.26 & 1.23 & 1.30 & (12) \\
\hline Turnbull et al, 2010 & SLC4A7 & rs4973768 & NM_001258379.1 & c. $* 4043+394 \mathrm{G}>\mathrm{A}$ & 1.33 & 1.07 & 1.64 & (13) \\
\hline Turnbull et al, 2010 & $C C N D 1$ & rs614367 & NC_000011.9 & g. $69328764 \mathrm{C}>\mathrm{T}$ & 1.15 & 1.10 & 1.20 & (13) \\
\hline $\begin{array}{l}\text { Easton et al, } 2007 \\
\text { and Stacey et al, } 2007\end{array}$ & TOX3 & rs3803662 & NC_000016.9 & g. $52586341 \mathrm{~A}>\mathrm{G}$ & 1.20 & 1.16 & 1.24 & $(12,14)$ \\
\hline Antoniou et al, 2004 & NUMAl & rs3018301 & NM_001145307.4 & c. $-140+140 A>G$ & 1.45 & 1.03 & 20.3 & (35) \\
\hline
\end{tabular}

SNP, single nucleotide polymorphism; OR, odds ratio; CI, confidence interval; HGV, human genome variation; COX11, cytochrome C oxidase copper chaperone; FGFR2, fibroblast growth factor receptor 2; SLC4A7, solute carrier family 4 member 7; CCND1, cyclin D1; TOX3, TOX high mobility group box family member 3; NUMA1, nuclear mitotic apparatus protein 1.

Table IV. Description of the cohort.

\begin{tabular}{|c|c|c|c|c|c|c|}
\hline Features & $\begin{array}{l}\text { Healthy } \\
\text { subjects }\end{array}$ & $\begin{array}{l}\text { Patients with } \\
\text { breast cancer }\end{array}$ & $\begin{array}{l}\text { Odds } \\
\text { ratio }\end{array}$ & \multicolumn{2}{|c|}{$\begin{array}{l}95 \% \text { confidence } \\
\text { interval }\end{array}$} & P-value \\
\hline Subjects & 92 & 52 & & & & \\
\hline $\begin{array}{l}\text { Age, years mean } \\
\text { (standard deviation) }\end{array}$ & $40.81(2.84)$ & $52.8(11.53)$ & & & & $<0.001$ \\
\hline Female & 62 & 50 & 7.79 & 2.57 & 33.8 & 0.001 \\
\hline$B R C A l$-mutated & 15 & 14 & 0.76 & 0.90 & 4.98 & 0.070 \\
\hline$B R C A 2$-mutated & 17 & 12 & 1.49 & 0.60 & 3.44 & 0.350 \\
\hline NUMAI & 28 & 12 & 0.87 & 0.30 & 1.91 & 0.730 \\
\hline$C C N D 1$ & 26 & 15 & 1.11 & 0.54 & 2.22 & 0.750 \\
\hline COX11 & 37 & 19 & 1.16 & 0.60 & 2.18 & 0.640 \\
\hline$F G F R 2$ & 81 & 41 & 1.30 & 0.50 & 3.22 & 0.550 \\
\hline тОХ3 & 63 & 26 & 0.81 & 0.40 & 1.40 & 0.450 \\
\hline SLC4A7 & 77 & 40 & 1.59 & 0.90 & 2.87 & 0.110 \\
\hline
\end{tabular}

BRCA1, breast cancer 1, early onset; BRCA2, breast cancer 2, early onset; NUMA1, nuclear mitotic apparatus protein 1; CCND1, cyclin D1; COX11, cytochrome C oxidase copper chaperone; FGFR2, fibroblast growth factor receptor 2; TOX3, TOX high mobility group box family member 3; SLC4A7, solute carrier family 4 member 7.

high risk of breast and other associated cancers (30). However, the majority of families with multiple patients with $\mathrm{BC}$ do not carry mutations in these genes (31). These observations have led to the proposal that BC susceptibility is largely polygenic, meaning that susceptibility is conferred by a large number of loci, each with a small effect on BC risk (32). This model is consistent with the observed patterns of familial aggregation of $\mathrm{BC}$.

A base for counseling may be provided by mathematical models, which predict BRCA1/2 carrier probabilities and cancer risk. A number of models have been suggested in the literature (15-21). Several of these are logistic regression models that use descriptive measures of family history and may be implemented by adding other non-genetic risk factors. An alternative approach is to base predictions on a genetic model for the disease, for example the Claus (15-16) or Gail models $(17,18,21)$. However, genetic susceptibility to
$\mathrm{BC}$ is more complex than these models suggest. As has been previously mentioned, BRCA1/2 genes explain just a small proportion of hereditary BC. Different studies focused on the association between $\mathrm{BC}$ risk and 8 common alleles, each conferring a relative $\mathrm{BC}$ risk $<1.5(14,32-34)$. It is important to highlight that the attributable risk of these alleles is relatively high (13-16\% for the allele of stronger effect) as they occur at a high frequency in the general population. However, the variants may only explain a proportion of $\mathrm{BC}$ when they perform a causal role $(33,34)$.

The present study focused on the estimation of $\mathrm{h}^{2}$ of BC susceptibility through 6 common variants used as instrumental variables in 52 Apulian nuclear families, with a relevant family history of BC. In addition, BC data analysis was performed for the first time by applying the ACE model on the liability scores, $Y^{*}$, of BC. This is defined by the liability of $\mathrm{BC}$ as predicted by SNPs that are not statistically associated with the 
Table V. $\mathrm{h}^{2}$ and covariate (none, sex/age and BCRA1/2) fixed effect estimates in (A) extended and (B) nuclear pedigrees.

A, Extended families

\begin{tabular}{|c|c|c|c|c|c|c|}
\hline Variable & $\begin{array}{l}\text { No covariates } \\
\text { estimate (SE) }\end{array}$ & $\mathrm{P}$-value & $\begin{array}{c}\text { Sex/age } \\
\text { estimate }(\mathrm{SE})\end{array}$ & P-value & $\begin{array}{c}\text { BRCA1/BRCA2 } \\
\text { estimate (SE) }\end{array}$ & P-value \\
\hline$h^{2}$ & $0.407(0.19)$ & $0.005^{\mathrm{a}}$ & $0.464(0.204)$ & $0.003^{\mathrm{a}}$ & $0.465(0.201)$ & $0.003^{\mathrm{a}}$ \\
\hline Sex & & & $0.295(0.197)$ & 0.681 & & \\
\hline Age & & & $0.003(0.006)$ & 0.137 & & \\
\hline BRCA1 & & & & & $0.405(0.24)$ & $0.092^{\mathrm{a}}$ \\
\hline BRCA2 & & & & & $-0.122(0.129)$ & 0.631 \\
\hline
\end{tabular}

B, Nuclear families

\begin{tabular}{|c|c|c|c|c|c|c|}
\hline Variable & $\begin{array}{l}\text { No covariates } \\
\text { estimate }(\mathrm{SE})\end{array}$ & P-value & $\begin{array}{c}\text { Sex/age } \\
\text { estimate }(\mathrm{SE})\end{array}$ & P-value & $\begin{array}{c}\text { BRCA1/BRCA2 } \\
\text { estimate (SE) }\end{array}$ & P-value \\
\hline$h^{2}$ & $0.359(0.17)$ & $0.009^{\mathrm{a}}$ & $0.394(0.18)$ & $0.006^{\mathrm{a}}$ & $0.339(0.19)$ & $0.022^{\mathrm{a}}$ \\
\hline Sex & & & $0.291(0.18)$ & 0.125 & & \\
\hline Age & & & $-0.003(0.006)$ & 0.631 & & \\
\hline BRCA1 & & & & & $0.386(0.211)$ & $0.067^{\mathrm{a}}$ \\
\hline BRCA2 & & & & & $-0.173(0.21)$ & 0.422 \\
\hline
\end{tabular}

${ }^{\mathrm{a}} \mathrm{P}<0.05$. BRCA1, breast cancer 1, early onset; BRCA2, breast cancer 2 , early onset; SE, standard error; $\mathrm{h}^{2}$, heritability.

disease, in addition to the unobserved terms representing the variation in liability of BC, unexplained by SNPs.

Family information and genotypes were used to estimate $\mathrm{h}^{2}$ in extended and nuclear pedigrees. Comparable results were obtained in the two cases $(0.407 \pm 0.19$ and $0.359 \pm 0.17$, respectively). This first result indicates a fairly strong additive genetic effect of BC susceptibility scores, $Y^{*}$. The possibility to analyze extended and nuclear pedigrees allows more precise and detailed estimations of variances to be obtained. However, no statistically significance was observed with household and sib-household effects, while the additive genetic component $\left(\mathrm{h}^{2}\right)$ was fairly strong and significant. It is not possible to compare the results of the present study with the literature as no other similar study regarding $\mathrm{BC} \mathrm{h}^{2}$ has been performed previously.

Antoniou et al (35) developed a model using complex segregation analysis of breast and ovarian cancer occurrence. It allowed for the simultaneous effect of BRCA1 and BRCA2 and the effect of low-penetrance genes with multiplicative effects on BC risk. The results of the present study demonstrated that the presence of deleterious mutations in BRCA1 genes have to be considered in the estimation of polygenic risk. The largest limitation of the present study was the sample size. The number of pedigrees and other SNPs correlated with BC by GWAS studies needs to be considered to improve the power of the study. It is important to highlight that $\mathrm{h}^{2}$ estimation is a snapshot of a moment in a limited geographical region and is not universally applicable.

Although the cohort size needs to be enlarged, the preliminary results are encouraging. The present study indicated the importance of the evaluation and consideration of the six SNPs, used as instrumental variables, in index patients in order to obtain improved genetic models useful for $\mathrm{h}^{2}$ analysis.

\section{Acknowledgements}

The present study was partially funded by Regione Puglia (DIEF 2011).

\section{References}

1. International Agency for Research on Cancer: http://globocan. iarc.fr Accessed November 15, 2015.

2. Colditz GA, Willett WC, Hunter DJ, Stampfer MJ, Manson JE, Hennekens $\mathrm{CH}$ and Rosner BA: Family history, age, and risk of breast cancer. Prospective data from the Nurses' Health Study. JAMA 270: 338-343, 1993.

3. Slattery ML, Berry TD and Kerber RA: Is survival among women diagnosed with breast cancer influenced by family history of breast cancer? Epidemiology 4: 543-548, 1993.

4. Pharoah PD, Day NE, Duffy S, Easton DF and Ponder BA: Family history and the risk of breast cancer: A systematic review and meta-analysis. Int J Cancer 71: 800-809, 1997.

5. Bevier M, Sundquist K and Hemminki K: Risk of breast cancer in families of multiple affected women and men. Breast Cancer Res Treat 132: 723-728, 2012.

6. Thompson D and Easton D: The genetic epidemiology of breast cancer genes. J Mammary Gland Biol Neoplasia 9: 221-236, 2004.

7. Chenevix-Trench G, Milne RL, Antoniou AC, Couch FJ, Easton DF and Goldgar DE: An international initiative to identify genetic modifiers of cancer risk in BRCA1 and BRCA2 mutation carriers: The Consortium of Investigators of Modifiers of BRCA1 and BRCA2 (CIMBA). Breast Cancer Res 9: 104, 2007. 
8. Breast Cancer Association Consortium: Commonly studied single-nucleotide polymorphisms and breast cancer: Results from the Breast Cancer Association Consortium. J Natl Cancer Inst 98: 1382-1396, 2006.

9. Sawyer S, Mitchell G, McKinley J, Chenevix-Trench G, Beesley J, Chen XQ, Bowtell D, Trainer AH, Harris M, Lindeman GJ and James PA: A role for common genomic variants in the assessment of familial breast cancer. J Clin Oncol 30: 4330-4336, 2012.

10. Visscher PM, Hill WG and Wray NR: Heritability in the genomics era-concepts and misconceptions. Nat Rev Genet 9: 255-266, 2008.

11. Ahmed S, Thomas G, Ghoussaini M, Healey CS, Humphreys MK, Platte R, Morrison J, Maranian M, Pooley KA, Luben R, et al: Newly discovered breast cancer susceptibility loci on 3p24 and 17q23.2. Nat Genet 41: 585-590, 2009.

12. Easton DF, Pooley KA, Dunning AM, Pharoah PD, Thompson D, Ballinger DG, Struewing JP, Morrison J, Field H, Luben R, et al: Genome-wide association study identifies novel breast cancer susceptibility loci. Nature 447: 1087-1093, 2007.

13. Turnbull C, Ahmed S, Morrison J, Pernet D, Renwick A, Maranian M, Seal S, Ghoussaini M, Hines S, Healey CS, et al: Genome-wide association study identifies five new breast cancer susceptibility loci. Nat Genet 42: 504-507, 2010.

14. Stacey SN, Manolescu A, Sulem P, Rafnar T, Gudmundsson J, Gudjonsson SA, Masson G, Jakobsdottir M, Thorlacius S, Helgason A, et al: Common variants on chromosomes $2 \mathrm{q} 35$ and $16 \mathrm{q} 12$ confer susceptibility to estrogen receptor-positive breast cancer. Nat Genet 39: 865-869, 2007.

15. Claus EB, Risch N and Thompson WD: The calculation of breast cancer risk for women with a first degree family history of ovarian cancer. Breast Cancer Res Treat 28: 115-120, 1993.

16. Claus EB, Risch N and Thompson WD: Autosomal dominant inheritance of early-onset breast cancer. Implications for risk prediction. Cancer 73: 643-651, 1994.

17. Gail MH, Brinton LA, Byar DP, Corle DK, Green SB, Schairer C and Mulvihill JJ: Projecting individualized probabilities of developing breast cancer for white females who are being examined annually. J Natl Cancer Inst 81: 1879-1886, 1989.

18. Parmigiani G, Berry D and Aguilar O: Determining carrier probabilities for breast cancer-susceptibility genes BRCA1 and BRCA2. Am J Hum Genet 62: 145-158, 1998.

19. Berry DA, Iversen ES Jr, Gudbjartsson DF, Hiller EH, Garber JE, Peshkin BN, Lerman C, Watson P, Lynch HT, Hilsenbeck SG, et al: BRCAPRO validation, sensitivity of genetic testing of BRCA1/BRCA 2 and prevalence of other breast cancer susceptibility genes. J Clin Oncol 20: 2701-2712, 2002.

20. Gail MH: Discriminatory accuracy from single-nucleotide polymorphisms in models to predict breast cancer risk. J Natl Cancer Inst 100: 1037-1041, 2008.

21. Gail MH: Value of adding single-nucleotide polymorphism genotypes to a breast cancer risk model. J Natl Cancer Inst 101: 959-963, 2009
22. Sobin LH: TNM, sixth edition: New developments in general concepts and rules. Semin Surg Oncol 21: 19-22, 2003.

23. Tommasi S, Crapolicchio A, Lacalamita R, Bruno M, Monaco A, Petroni S, Schittulli F, Longo S, Digennaro M, Calistri D, et al: BRCA1 mutations and polymorphisms in a hospital-based consecutive series of breast cancer patients from Apulia, Italy. Mutat Res 578: 395-405, 2005.

24. Team R.C.D: R: A Language and Environment for Statistical Computing. R Foundation for Statistical Computing, 2005.

25. Benchek PH and Morris NJ: How meaningful are heritability estimates of liability? Hum Genet 132: 1351-1360, 2013.

26. Muthén LK and Muthén B: Mplus User's Guide. 6th edition. CA, Muthén \& Muthén, Los Angeles, 2010.

27. Almasy L and Blangero J: Multipoint quantitative-trait linkage analysis in general pedigrees. Am J Hum Genet 62: 1198-1211, 1998.

28. Neale M and Cardon L: Methodology for genetic studies of twins and families. Kluwer Academic Publishers B.V.Dordrecht, The Netherlands, 1992.

29. Familial breast cancer: Collaborative reanalysis of individual data from 52 epidemiological studies including 58,209 women with breast cancer and 101,986 women without the disease. Lancet 358: 1389-1399, 2001.

30. Antoniou A, Pharoah PD, Narod S, Risch HA, Eyfjord JE, Hopper JL, Loman N, Olsson H, Johannsson O, Borg A, et al: Average risks of breast and ovarian cancer associated with BRCA1 or BRCA2 mutations detected in case Series unselected for family history: A combined analysis of 22 studies. Am J Hum Genet 72: 1117-1130, 2003.

31. Smith P, McGuffog L, Easton DF, Mann GJ, Pupo GM, Newman B, Chenevix-Trench G; kConFab Investigators, Szabo C, Southey M, et al: A genome wide linkage search for breast cancer susceptibility genes. Genes Chromosomes Cancer 45: 646-655, 2006.

32. Hunter DJ, Kraft P, Jacobs KB, Cox DG, Yeager M, Hankinson SE, Wacholder S, Wang Z, Welch R, Hutchinson A, et al: A genome-wide association study identifies alleles in FGFR2 associated with risk of sporadic postmenopausal breast cancer. Nat Genet 39: 870-874, 2007.

33. Cox A, Dunning AM, Garcia-Closas M, Balasubramanian S, Reed MW, Pooley KA, Scollen S, Baynes C, Ponder BA, Chanock S, et al: A common coding variant in CASP8 is associated with breast cancer risk. Nat Genet 39: 352-358, 2007.

34. Zhang B, Beeghly-Fadiel A, Long J and Zheng W: Genetic variants associated with breast-cancer risk: Comprehensive research synopsis, meta-analysis, and epidemiological evidence. Lancet Oncol 12: 477-488, 2011.

35. Antoniou AC, Pharoah PP, Smith P and Easton DF: The BOADICEA model of genetic susceptibility to breast and ovarian cancer. Br J Cancer 91: 1580-1590, 2004. 